\title{
Non-Enzymatic Glucose Oxidation at Electrocatalytic Metal Oxide Films
}

\author{
R. L. Doyle ${ }^{\mathrm{a}}$, G. Komarkova ${ }^{\mathrm{b}}$, P. O’Brien ${ }^{\mathrm{a}}$ and M. E. G. Lyons ${ }^{\mathrm{a}}$ \\ ${ }^{a}$ Trinity Electrochemical Energy Conversion \& Electrocatalysis (TEECE) Group, \\ School of Chemistry \& CRANN, Trinity College, Dublin 2, Ireland. \\ ${ }^{\mathrm{b}}$ Department of Chemistry, Palacky University, Olomouc, Czech Republic.
}

The electro-oxidation of glucose at nickel hydroxide films is discussed. These films can be electrodeposited using a simple potential multi-cycling procedure. The resulting films exhibit a nanostructured surface morphology. Cyclic voltammetry, rotatingdisk electrode voltammetry and electrochemical impedance spectroscopy have been used to elucidate the kinetics and mechanism of the oxidation of glucose. $\mathrm{NiOOH}$ is shown to be the active form of the nickel hydroxide layer and the impedance data indicates significant surface adsorption at these sites. Furthermore, mass-transport-corrected Tafel slopes of ca. 40 and $60 \mathrm{mV} / \mathrm{dec}$ were observed at low and high potentials respectively identifying a change in rate-control with increasing potential. Finally, we show using amperometric techniques that this simple modified electrode possesses excellent sensitivity for the oxidation of glucose, displaying current increases of $c a .3 .7 \mathrm{~mA} \mathrm{mM}^{-1} \mathrm{~cm}^{-2}$ with a limit of detection of the order of $2.0 \mu \mathrm{M}$ glucose.

\section{Introduction}

The electro-oxidation of glucose is an electrocatalytic process of vital modern importance (1-6). Sensitive and selective glucose detection has demonstated applications not only in blood sugar monitoring but also in the food industry, bio-processing and in the development of renewable, sustainable fuel cells. In all cases the dominant approach involves the use of biocatalysts such as enzymes and microorganisms. For example, virtually all commercial blood glucose monitors employ enzymatic electrodes which are predominantly based on the enzyme glucose oxidase $(\mathrm{GOX})(2,3)$. While this approach has been highly successful, accounting for approximately $85 \%$ of the biosensor industry (3), the enzymatic detection of glucose suffers from a number of drawbacks. Enzymes are notoriously difficult to work with, and although GOX is relatively robust in terms of its tolerance for changes in temperature and $\mathrm{pH}$ (4), enzyme stability during both fabrication and operation is still an issue. As a result, enzymatic electrodes are often quite costly to produce and suffer from low reproducibility and a short lifespan.

In recent years non-enzymatic glucose sensors have received a considerable amount of interest $(5,6)$. This method involves the direct oxidation of glucose at the surface of an electrocatalytic electrode material. A number of promising electrode materials have been studied for the catalytic oxidation of glucose including electrocatalytic metals such as platinum (7), gold (8), nickel (9), and copper (10), as well as various carbon based materials (11). Nickel electrodes in particular have been explored extensively as 
electrocatalyst materials. It has been established that the catalytic species is a $\mathrm{Ni}$ (III) oxyhydroxide; the oxidised form of the nickel oxide/hydroxide surface (9a-d, 12). This species can irreversibly oxidise glucose while being itself reduced to a $\mathrm{Ni}$ (II) species, typically $\mathrm{Ni}(\mathrm{OH})_{2}$. The active $\mathrm{Ni}(\mathrm{III})$ form can subsequently be regenerated via continued oxidation of the nickel surface, resulting in the catalytic cycle depicted in Fig. 1. Hence the metal oxide fulfils the role of both catalyst and redox mediator. The attraction of this approach is obvious as it dispenses with the need to use fragile and relatively temperamental enzymes, thereby increasing both the simplicity and stability of the electrode device (5). In addition, non-enzymatic electrodes typically possess superior electrocatalytic properties to those of their enzymatic counterparts, making them highly sensitive glucose sensors and efficient electrocatalysts for the fuel cell industry $(9 \mathrm{~g}, 13)$.

In the present work we focus on the electro-oxidation of glucose at nickel hydroxide films in alkaline solution. As previously mentioned, the use of nickel oxide/hydroxide electrodes as electrochemical glucose sensors is well established (9). These modified electrodes are commonly prepared using potentiostatic or galvanostatic deposition methods. Here, we report for the first time the electrocatalytic oxidation of glucose at nickel hydroxide layers prepared using a repetitive potential cycling technique. The electrocatalytic properties of the nickel oxide layer towards glucose oxidation are examined using a combination of cyclic voltammetry, rotating disk electrode voltammetry and electrochemical impedance spectroscopy. Furthermore, we show using amperometric techniques that this simple modified electrode exhibits excellent sensitivity and stability for the oxidation of glucose.

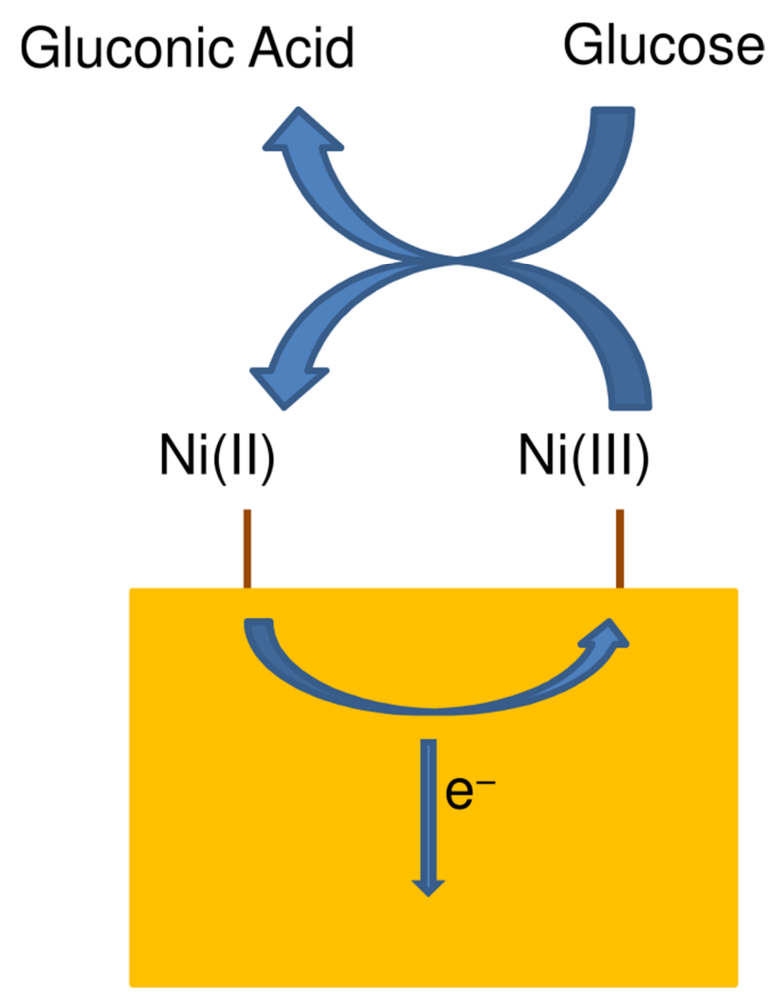

Figure 1. General catalytic cycle depicting the electro-oxidation of glucose at a nickel oxide/hydroxide surface. 


\section{Experimental}

\section{$\underline{\text { General Setup }}$}

All reagents were used as supplied. D-(+)-glucose $(\geq 99.5 \%)$, sodium hydroxide $(\geq 99.0 \%)$ and potassium hydroxide $(\geq 85 \%)$ were obtained from Sigma-Aldrich. Nickel(II) sulphate hexahydrate $(\geq 99.0 \%)$ was purchased from $\mathrm{BDH}$ and sodium acetate trihydrate $(\geq 99 \%)$ was supplied by Riedel de Haën. Aqueous solutions were prepared using Millipore water (resistivity $>15 \mathrm{M} \Omega \mathrm{cm}$ ) and the solutions were bubbled with nitrogen gas for $20 \mathrm{~min}$ before commencing each experiment.

A standard three electrode cell was used for all electrochemical experiments. The working electrode was either a gold disk electrode (CH Instruments, CHI 101) with a geometric surface area of $0.031 \mathrm{~cm}^{2}$ or a gold rotating disk electrode (Pine, E6 series) with a geometric surface area of $0.196 \mathrm{~cm}^{2}$. Prior to each experiment the surface of the working electrode was polished successively with 1200 grit carbimet paper and a slurry of $0.3 \mu \mathrm{m}$ alumina powder until a "mirror bright" finish was achieved. A platinum wire electrode ( $\mathrm{CH}$ Instruments, $\mathrm{CHI} 115)$ was employed as the counter electrode. Two reference electrodes were used depending on the solution conditions; a mercury-mercuric oxide $(\mathrm{Hg} / \mathrm{HgO})$ reference electrode $(\mathrm{CH}$ Instruments, $\mathrm{CHI} 152)$ was utilised in alkaline solutions and a silver/silver chloride $(\mathrm{Ag} / \mathrm{AgCl})$ reference electrode (ALS, 012167) was the reference standard for the electrodeposition procedure.

The electrochemical measurements, with the exception of electrochemical impedance spectroscopy, were performed using a CHI760E bipotentiostat. Rotating disk electrode voltammetry was performed using a Pine MSR rotator unit. Electrochemical impedance spectroscopy was performed using a Zahner Elektrik IM6 electrochemical measurement unit. The impedance spectra were recorded by employing a $5 \mathrm{mV}$ peak to peak amplitude sine wave potential perturbation on the dc potential. The dc potential was changed step wise in the positive direction, with sufficiently long delays to achieve steady state conditions. This has been checked by applying Kramers-Kronig tests to the measured spectra. Complex non-linear least squares (CNLS) fitting of raw impedance data to equivalent circuit models was conducted using the SIM module of the IM6 Thales software suite.

Scanning electron microscopy (SEM) was performed using a Zeiss Ultra Plus equipped with a high resolution $(<1 \mathrm{~nm})$ field emission SEM and a Gemini ${ }^{\circledR}$ column.

\section{Preparation of the Nickel Hydroxide Films}

Nickel hydroxide films were prepared using a method previously outlined by Fantini and Gorenstein (14). The nickel hydroxide films were electrodeposited on a gold electrode from an aqueous solution containing $0.1 \mathrm{M} \mathrm{NiSO}_{4}, 0.1 \mathrm{M} \mathrm{CH}_{3} \mathrm{COONa}$ and $0.001 \mathrm{M} \mathrm{KOH}$. The electrodeposition was performed potentiodynamically by repetitively scanning the potential between $-0.865 \mathrm{~V}$ and $1.235 \mathrm{~V}$ vs. $\mathrm{Ag} / \mathrm{AgCl}$ at a scan rate of 20 $\mathrm{mV} \mathrm{s}^{-1}$ for a total of 30 cycles. The electrode was then removed from the polymerisation solution, rinsed with Millipore water and transferred to the analytical solution. 


\section{Results and Discussion}

\section{Nickel Hydroxide Electrodeposition}

A series of cyclic voltammograms recorded during the electrodeposition process are presented in Fig. 2. It is clear that the electrodeposition process performed in this manner is quite complex. Two clear oxidation peaks can be observed at $c a$. $-0.4 \mathrm{~V}$ and $0.9 \mathrm{~V}$ which are most likely the result of $\mathrm{Ni}(0) / \mathrm{Ni}(\mathrm{II})$ and $\mathrm{Ni}(\mathrm{II}) / \mathrm{Ni}(\mathrm{III})$ redox transitions respectively (15). On the other hand up to four reduction waves can be discerned on the reverse cathodic cycle between $1.0 \mathrm{~V}$ and $0 \mathrm{~V}$. The assignment of these peaks is considerably less facile and will not be discussed here. However, we note that the electrodeposition process may proceed as follows (16):

$$
\mathrm{Ni}^{2+}{ }_{(\mathrm{aq})}+2 \mathrm{OH}^{-} \rightarrow \mathrm{Ni}(\mathrm{OH})_{2}
$$

The following process may also occur as the potential is cycled anodically:

$$
\begin{gathered}
\mathrm{OH}^{-} \rightarrow \mathrm{OH}_{\text {ads }}+\mathrm{e}^{-} \\
\mathrm{Ni}^{2+}{ }_{(\mathrm{aq})}+\mathrm{H}_{2} \mathrm{O}+\mathrm{OH}_{\text {ads }} \rightarrow \mathrm{NiOOH}+2 \mathrm{H}^{+}{ }_{(\mathrm{aq})}
\end{gathered}
$$

In addition the following process may occur in solution:

$$
\begin{array}{r}
\mathrm{Ac}^{-}+\mathrm{H}_{2} \mathrm{O} \rightarrow \mathrm{HAc}+\mathrm{OH}^{-} \\
\mathrm{Ni}^{2+}{ }_{(\mathrm{aq})}+\mathrm{OH}^{-} \rightarrow \mathrm{NiOH}{ }^{+} \\
\mathrm{NiOH}^{+}+\mathrm{OH}_{\mathrm{ads}} \rightarrow \mathrm{NiOOH}+2 \mathrm{H}^{+}
\end{array}
$$

where $\mathrm{Ac}^{-}=\mathrm{CH}_{3} \mathrm{COO}^{-}$. Hence it is likely that both $\mathrm{Ni}(\mathrm{OH})_{2}$ and $\mathrm{NiOOH}$ can be formed during the course of the potential sweep perturbation.

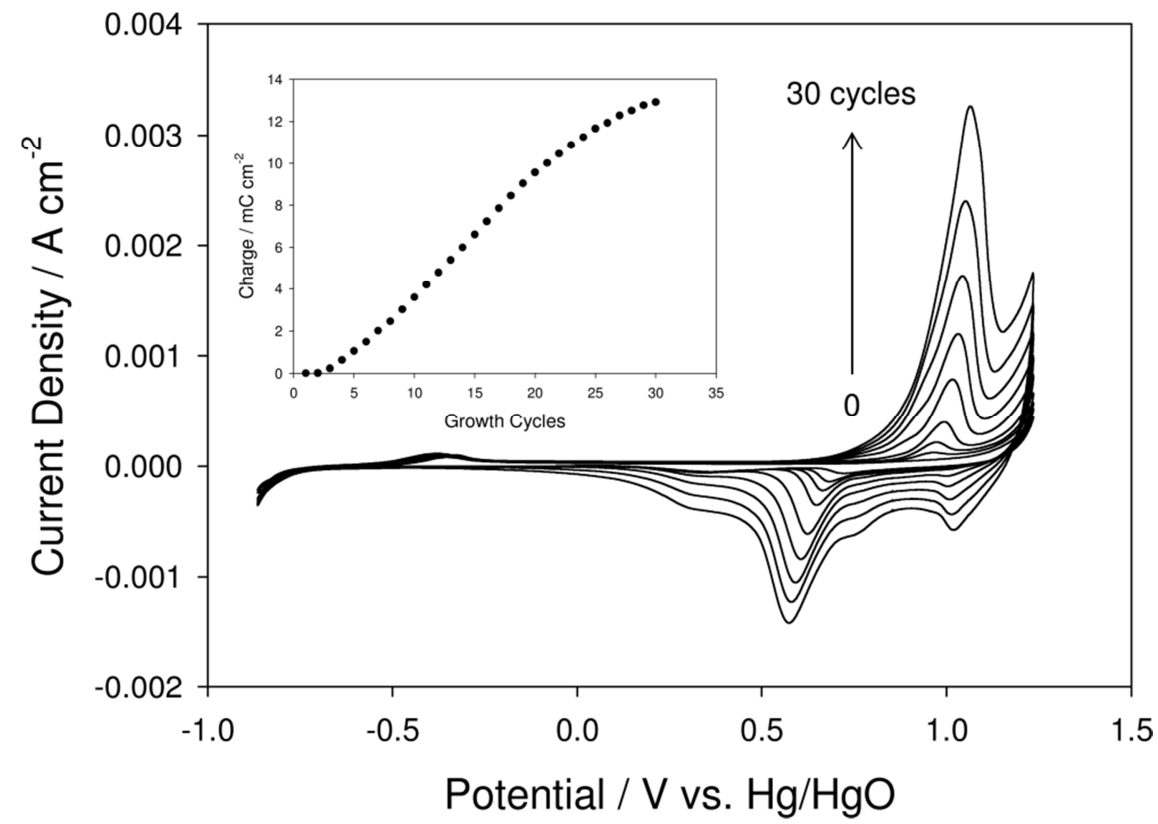

Figure 2. Cyclic voltammograms recorded during the growth of the nickel hydroxide layer. Inset: The redox charge capacity $Q$ plotted as a function of the number of growth cycles. 
One of the advantages of the potentiodynamic method outlined above is that the growth of the nickel hydroxide film can be monitored in real time by following the development of the redox peaks. This is illustrated in the inset of Fig. 2 where a plot of the redox charge capacity $\mathrm{Q}$, which is directly proportional to the layer thickness and can be obtained by integration of the area under the main anodic peak at $c a .0 .9 \mathrm{~V}$, is plotted as a function of the number of electrodeposition cycles. The slightly sigmoidal shape of this plot suggests an initial activation period where the film growth kinetics are slow. This may involve the adsorption of $\mathrm{OH}^{-}$as depicted in eqn[2]. Following this activation period the electrodeposition process becomes more facile and $\mathrm{Q}$ is found to increase in a linear fashion with each successive cycle. Finally, for higher numbers of growth cycles the growth rate decreases and $\mathrm{Q}$ tends towards a limiting value. In this respect it is interesting to note that the peak potential for the corresponding oxidation peak shifts to more positive values with increasing number of growth cycles. This is indicative of the formation of an increasingly resistive film on the electrode surface as the layer of nickel hydroxide increases in thickness and may account for the reduction in growth rate observed in the inset of Fig. 2.

\section{$\underline{\text { Surface Characterisation of the Nickel Hydroxide Film }}$}

Scanning Electron Microscopy (SEM). Information on the surface morphology of the nickel hydroxide layer was obtained using SEM. Fig. 3 shows SEM micrographs recorded for a nickel hydroxide modified $\mathrm{Au}$ electrode. It is clear from Fig. 3a that the nickel hydroxide layer possesses a highly porous surface morphology. It is should also be noted that the nickel hydroxide layer does not deposit uniformly on the Au electrode surface. Instead, several regions exhibiting limited or no film growth are evident in Fig. 3a. An image of one such region at higher magnification is shown in Fig. 3b. In this region of limited film growth it is possible to obtain a better idea of the actual structure of the electrodeposit. It appears that nickel hydroxide deposited in this manner consists of aggregates of particles, possibly nanoparticles. The formation of nickel hydroxide particles has also been reported by Toghill et al. (9g) and Hutton et al. (9f). These authors observed random microparticle arrays and discrete nanoparticles respectively for potentiostatically deposited nickel hydroxide layers.

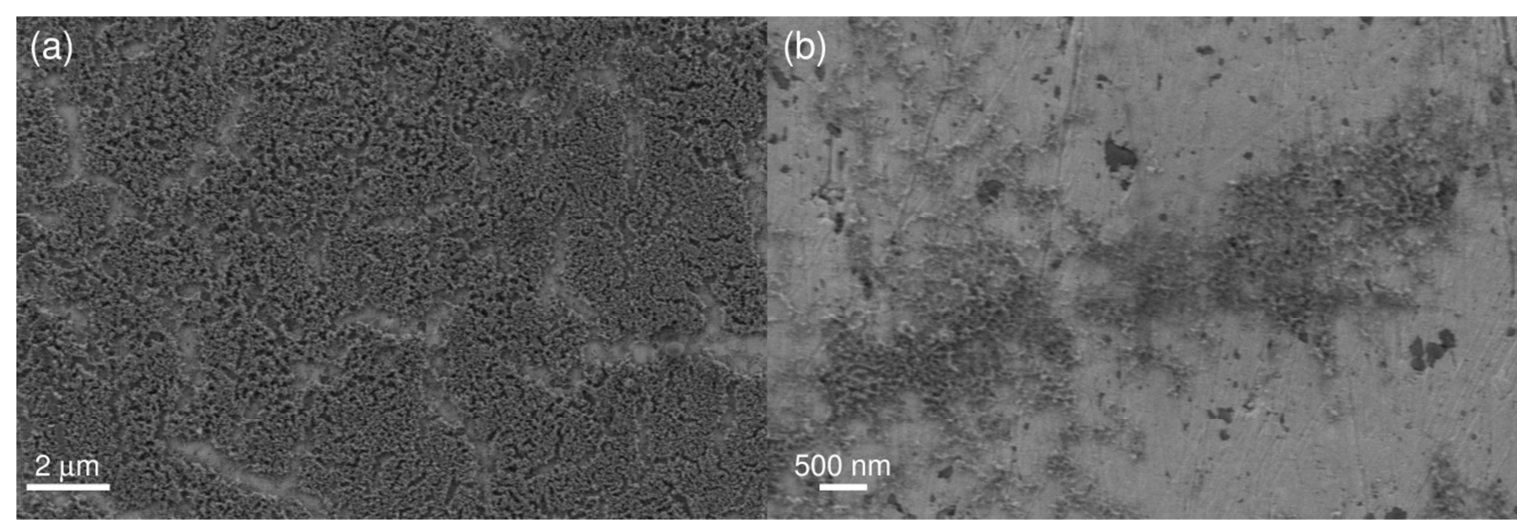

Figure 3. (a) SEM image recorded for a nickel hydroxide modified Au electrode. (b) Higher magnification image of a region with low a level of nickel hydroxide coverage. 
Cyclic Voltammetry (CV). The interfacial redox chemistry of the nickel hydroxide layer was studied using cyclic voltammetry. Fig. 4a shows a typical CV recorded in 1.0 $\mathrm{M} \mathrm{NaOH}$ for a nickel hydroxide modified $\mathrm{Au}$ electrode. The major feature of the voltammetric response is a redox couple centred at $c a .0 .43 \mathrm{~V}$ corresponding to a $\mathrm{Ni}(\mathrm{II}) / \mathrm{Ni}$ (III) transition. The general features of the $\mathrm{Ni}(\mathrm{II}) / \mathrm{Ni}(\mathrm{III})$ redox transition can be readily understood using the Bode scheme shown in Fig. 4b (17). The electrodeposition of nickel hydroxide is known to produce two crystallographic forms; a hydrated $\alpha$ $\mathrm{Ni}(\mathrm{OH})_{2}$ phase and an anhydrous $\beta-\mathrm{Ni}(\mathrm{OH})_{2}$ phase. In this model, oxidation of the $\alpha-$ and $\beta$ - phases is envisaged to produce $\gamma-\mathrm{NiOOH}$ and $\beta-\mathrm{NiOOH}$ respectively. Thus one may expect two distinct redox peaks for the $\mathrm{Ni}(\mathrm{II}) / \mathrm{Ni}(\mathrm{III})$ transition: $\alpha / \gamma$ and $\beta / \beta$. This is evident in Fig. 4a from the cathodic doublet centered at $c a .0 .38 \mathrm{~V}$. Lyons and coworkers (16a) have recently assigned these peaks to the $\alpha / \gamma(0.36 \mathrm{~V})$ and $\beta / \beta(0.41 \mathrm{~V})$ phases based on their characteristic potential-pH shifts. It was found that the peak at $c a .0 .41 \mathrm{~V}$ exhibited a regular Nernstian shift in the region of $-59 \mathrm{mV} / \mathrm{dec}$, whereas super-Nernstian potential-pH shifts of $c a .-75 \mathrm{mV} / \mathrm{dec}$ characteristic of a hydrated oxide were observed for the peak at ca. $0.36 \mathrm{~V}$. In contrast, it was difficult to distinguish between the $\alpha$ - and $\beta$ transitions on the anodic sweep in Fig. 4a. The anodic peak located at $c a$. $0.49 \mathrm{~V}$ showed very little fine structure, although a slight shoulder can be discerned at $c a .0 .47 \mathrm{~V}$. In addition the broad nature of the anodic wave suggests that the $\alpha$ - and $\beta$-phases are oxidized over a similar potential range.
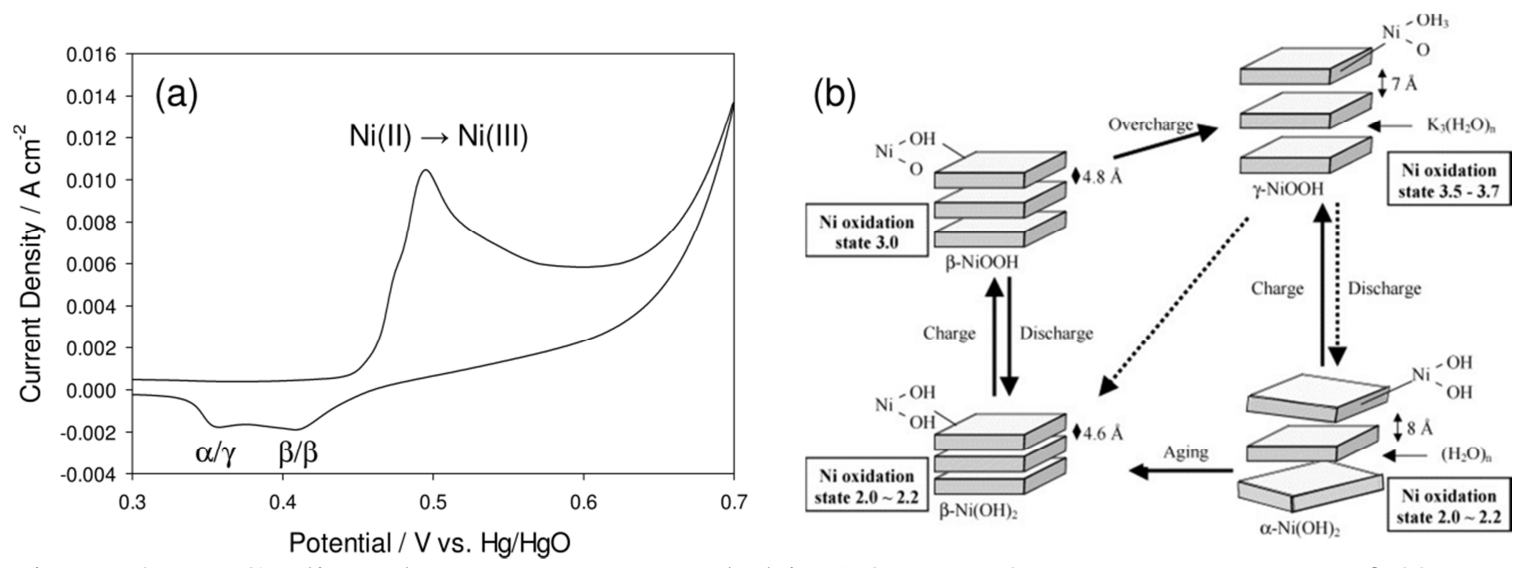

Figure 4. (a) Cyclic voltammogram recorded in $1.0 \mathrm{M} \mathrm{NaOH}$ at a sweep rate of $40 \mathrm{mV}$ $\mathrm{s}^{-1}$ for a nickel hydroxide modified Au electrode. (b) Schematic representation of the Bode cycle for the $\mathrm{Ni}(\mathrm{II}) / \mathrm{Ni}$ (III) redox transition in nickel hydroxide layers (17).

\section{Nickel Hydroxide Electrocatalysis of Glucose Oxidation}

Cyclic Voltammetry. The electro-oxidation of glucose at the nickel hydroxide film was investigated in $1.0 \mathrm{M} \mathrm{NaOH}$ solutions. A series of CVs recorded for the nickel hydroxide modified gold electrode in varying concentrations of glucose are shown in Fig. 5. A number of features should be noted. Firstly, the anodic peak is observed to increase significantly with increasing glucose concentration. This can be attributed to the catalytic regeneration of the $\mathrm{Ni}(\mathrm{OH})_{2}$ species by the irreversible oxidation of glucose as shown in Fig. 1. Accordingly a relatively smaller current is generated by the reduction of the $\mathrm{NiOOH}$ species and the cathodic peak decreases with increasing glucose concentration. In this respect it is interesting to note that the $\beta$ reduction peak decreases to a much greater extent than the $\gamma$ peak. Indeed, for glucose concentrations greater than $10 \mathrm{mM}$ the 
$\beta$ peak is no longer present. This suggests that $\beta-\mathrm{NiOOH}$ is the dominant catalytic species, a concept that has been discussed extensively in the literature $(9 \mathrm{a}, 12,18)$. The catalytic oxidation of glucose is also evident on the reverse sweeps in Fig. 5. Further oxidative currents can be observed as the potential is swept negatively until potentials where the $\mathrm{NiOOH}$ species is reduced are reached, and the surface becomes electrocatalytically inactive again. Finally, we note that the anodic peak potential shifts positively with increasing glucose concentration. The reason for this is unclear, however similar observations have also been made by Toghill and Compton (5). These authors suggest that the shift in peak potential is indicative of a rapid and prolonged oxidation cycle, possibly coupled with a gradual change in local $\mathrm{pH}$ of the electrode surface.

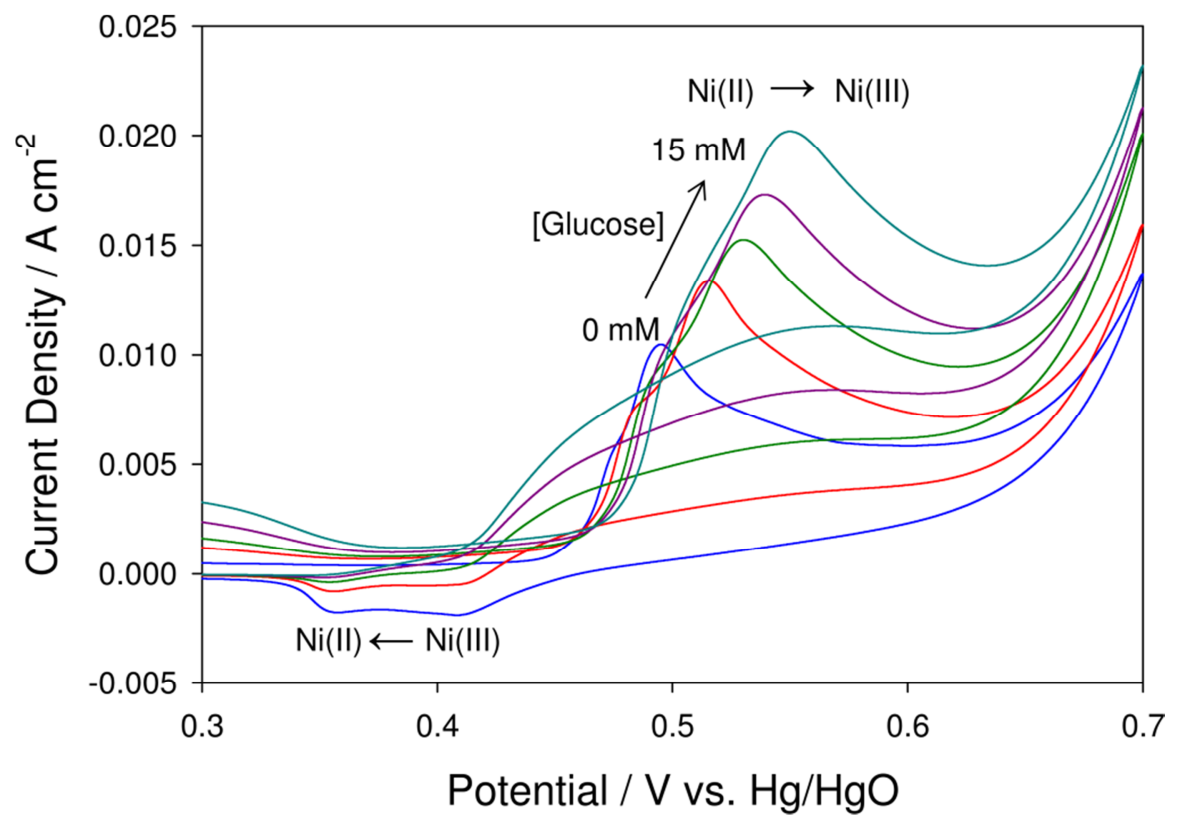

Figure 5. Cyclic voltammograms recorded in a $1.0 \mathrm{M} \mathrm{NaOH}$ solution containing various concentrations of glucose at $40 \mathrm{mV} \mathrm{s}^{-1}$ for a nickel hydroxide modified Au electrode.

Mass-Transport-Corrected Tafel Analysis. Rotating-disk electrode (RDE) voltammetry was employed to examine the kinetics of glucose oxidation at the nickel hydroxide layer. Fig. 6a shows typical RDE voltamograms recorded for the nickel hydroxide modified Au electrode in a $15 \mathrm{mM}$ glucose solution at rotation speeds of 500 and $1500 \mathrm{rpm}$. It should be noted that mass-transport limitation of the current response is observed at potentials where the nickel hydroxide layer is expected to be primarily in the oxidized $\mathrm{NiOOH}$ form. That is, the reaction becomes diffusion controlled when the concentration of catalyst is maximized. Further kinetic information can be obtained from the RDE data utilizing the mass-transport-corrected Tafel equation for a net oxidation process which is given by,

$$
\log \left[i i_{\mathrm{L}} /\left(i_{\mathrm{L}}-i\right)\right]=\alpha \Theta+\log i^{0}
$$

where $\Theta$ is a normalized potential given by,

$$
\Theta=F\left(E-E^{0}\right) / 2.303 R T
$$

$\alpha$ is the transfer coefficient and $i^{0}$ is the exchange current density given by, 


$$
i^{0}=n F A k^{0} c^{\infty}
$$

where $c^{\infty}$ is the bulk concentration of the reactant and all other symbols have their usual meaning (19). It can be seen from the above analysis that a plot of the log of the masstransport-corrected current function $i i_{\mathrm{L}} /\left(i_{\mathrm{L}}-i\right)$ vs. the potential will yield a straight line relationship with slope equal to the Tafel slope. Mass-transport-corrected Tafel plots generated from the RDE voltammograms in Fig. 6a are presented in Fig. 6b. Two distinct linear regions were observed over the potential range where the current was kinetically limited, i.e. the rising portion of the voltammograms in Fig. 6a. Tafel slopes of ca. $40 \mathrm{mV} / \mathrm{dec}$ were determined in the low potential region increasing to $c a .60 \mathrm{mV} / \mathrm{dec}$ at higher potentials. These results indicate a change in the rate-determining step (RDS) for glucose electro-oxidation as the potential is increased; possibly from an electron-transfer step at low potentials to a chemical step at higher potentials. This concept is discussed in more detail in a subsequent section concerning the mechanism of glucose electrooxidation at the nickel hydroxide modified Au electrode.
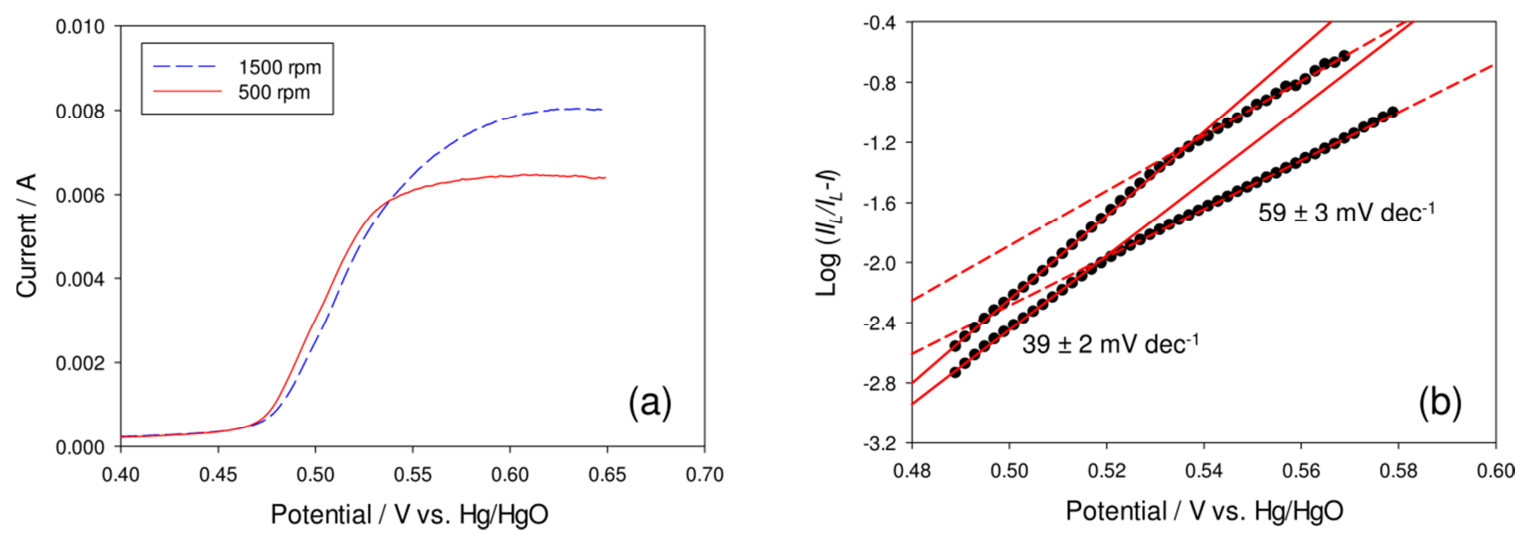

Figure 6. (a) Rotating-disk electrode voltammograms recorded in a $1.0 \mathrm{M} \mathrm{NaOH}$ solution containing $15 \mathrm{mM}$ glucose at a sweep rate of $5 \mathrm{mV} \mathrm{s}^{-1}$ and various electrode rotation speeds for a nickel hydroxide modified Au electrode. (b) Mass-transport-corrected Tafel plots generated from the data in Fig. 6a using eqn[7].

Electrochemical Impedance Spectroscopy (EIS). The electrocatalytic properties of the nickel hydroxide film towards glucose electro-oxidation were further investigated using EIS. The electrochemical impedance response of the nickel hydroxide modified electrode was recorded over a range of potentials associated glucose oxidation, in solutions containing various glucose concentrations. A series of impedance spectra recorded in a $10 \mathrm{mM}$ glucose solution are presented in the Nyquist and Bode/Phase format in Fig. 7. These spectra are representative of the impedance response in all glucose concentrations studied. The raw impedance data was fitted, using a CNLS fitting algorithm, to the equivalent circuit model depicted in the inset of Fig.7a and the simulated data is presented in Fig. 7 as a continuous line. The best-fit values of the equivalent circuit elements from the CNLS fitting procedure are listed in Table I. 

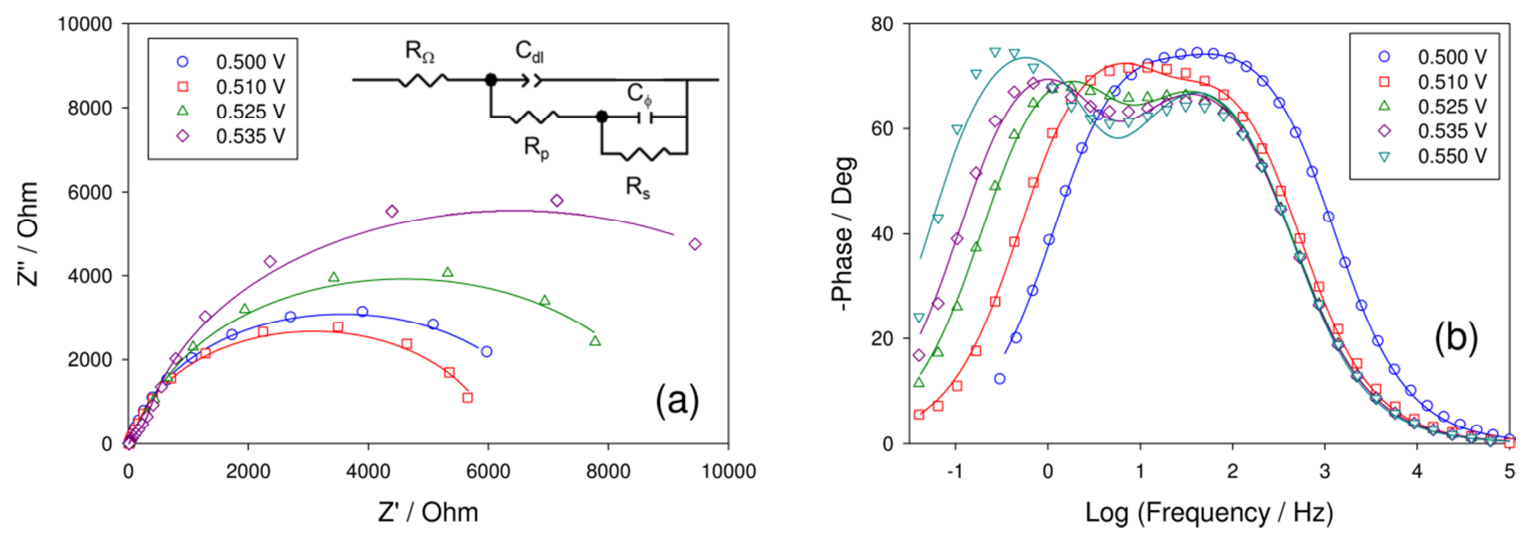

Figure 7. Electrochemical impedance spectra recorded in a $1.0 \mathrm{M} \mathrm{NaOH}$ solution containing $10 \mathrm{mM}$ glucose at a series of potentials associated with glucose oxidation for a nickel hydroxide modified Au electrode in (a) the Nyquist and (b) Bode/phase format. The experimental data is represented by discrete points and the simulated impedance response generated using the equivalent circuit in the inset of Fig. 7a is represented by a continuous line.

TABLE I. Optimum fit parameters for the CNLS fitting of the impedance data in Fig. 7 to the equivalent circuit model in the inset of Fig. 7a.

\begin{tabular}{cccccc}
\hline $\boldsymbol{E} / \mathbf{V}$ & $\boldsymbol{R}_{\boldsymbol{\Omega}} / \boldsymbol{\Omega}$ & $\boldsymbol{C}_{\boldsymbol{d l}} / \mathbf{\mathbf { m F }} \mathbf{~ c m}^{-\mathbf{2}}$ & $\boldsymbol{R}_{p} / \boldsymbol{\Omega}$ & $\boldsymbol{C}_{\boldsymbol{\phi}} / \mathbf{m F ~ \mathbf { ~ m } ^ { - 2 }}$ & $\boldsymbol{R}_{\boldsymbol{s}} / \boldsymbol{\Omega}$ \\
\hline 0.500 & 13.68 & 0.301 & 2274 & 0.122 & 4791 \\
0.510 & 13.71 & 0.663 & 936 & 0.358 & 5184 \\
0.525 & 13.62 & 0.756 & 1069 & 1.000 & 8034 \\
0.535 & 13.63 & 0.761 & 1056 & 1.457 & 11720 \\
0.550 & 13.78 & 0.790 & 874 & 1.972 & 21930 \\
\hline
\end{tabular}

Note: Mean $\alpha$ values of $0.89 \pm 0.02$ were obtained for $\mathrm{C}_{\mathrm{dl}}$.

In general, the impedance spectra were characterised by two relaxation processes. This is clear from the two distinct capacitance peaks, modelled in order of decreasing frequency by the $C_{d l}$, and $C_{\phi}$ circuit elements, in the Bode/Phase plots of Fig. 7b. In this model the $C_{d l}$ element represents the double-layer capacitance, while $R_{\Omega}$ represents the electrolyte resistance. The resistive elements $R_{s}$ and $R_{p}$ are related to the kinetics of the interfacial charge transfer reaction. In accordance with the work of Harrington and Conway (20), $R_{p}$ and $R_{s}$ cannot be interpreted simply as successive charge transfer resistances for individual reaction steps but, are each instead attributed to the properties of two or more steps in the overall reaction. Following the assertions of the same authors, the appearance of a second relaxation process is indicative of the adsorption of intermediates. Therefore, $C_{\phi}$ is given the value of a capacitor which in parallel with $R_{s}$ correctly models the relaxation of the charge associated with an important surface intermediate. While it is tempting to interpret $C_{\phi}$ as the steady-state adsoption pseudocapacitance (21), Harrington and Conway (20) have shown that, in the general case, there is no simple relationship between these two quantities.

One further point regarding the equivalent circuit analysis was the necessity to use a constant phase element (CPE) in place of a pure capacitor for the double-layer capacitance. CPEs are commonly used to simulate frequency dispersion in the various capacitive responses of a system. Such frequency dispersion is believed to arise from surface roughness and inhomogeneity (22). The impedance $Z_{C P E}$ of a capacitive process displaying frequency dispersion is expressed as, 


$$
Z_{C P E}=A(j \omega)^{-\alpha}
$$

where $A=1 / C_{a=1}, C_{a=1}$ is the value of the capacitance in the absence of frequency dispersion and $\alpha$ is an exponent equal to unity for an ideal capacitor and $\alpha \leq 1$ for all other physically reasonable situations. The result of a CNLS fitting of the raw impedance data to a CPE using the Thales SIM program, is an output in the form of optimised values for $C_{\alpha=1}$ and $\alpha$. While the physical significance of the $\alpha$ parameter is uncertain, it is reasonable to conclude that the smaller the value of $\alpha$ the less uniform the electrode surface. Therefore, with increasing surface roughness and dispersion, the magnitude of $\alpha$ will decrease as the classical concept of the double layer capacitance of an ideally smooth uniform electrode/solution interface becomes progressively less applicable. Taking this into consideration, the average $\alpha$ values listed in Table I for $C_{d l}$ suggest that the nickel hydroxide layer exhibits significant surface roughness, in agreement with the SEM results outlined above (Fig. 3).

In order to gain a better understanding of the electro-oxidation of glucose at the nickel hydroxide modified electrode, we now conduct a closer examination of the individual contributions to the overall Faradaic impedance. The fitting values obtained for the $C_{d l} R_{p}$ and $C_{\phi} R_{S}$ loops in the equivalent circuit model are plotted as a function of applied potential in Fig. 8. Fig. 8a shows the potential dependence of the double layer capacitance. It was found that the value of $C_{d l}$ increased from ca. $220 \mu \mathrm{F} \mathrm{cm}^{-2}$ to almost $800 \mu \mathrm{F} \mathrm{cm} \mathrm{cm}^{-2}$. Such elevated values of $C_{d l}$, in comparison with a typical double-layer capacitance, are to be expected for an electrode modified with a surface deposit and are indicative of significant surface roughness. The fact that the increase in the surface capacitance occurs near the $\mathrm{Ni}$ (II)/ $\mathrm{Ni}$ (III) peak potential, which occurs at $0.5 \mathrm{~V}$ in $10 \mathrm{mM}$ glucose, suggests that it is related to the change in nickel oxidation state. The transition from a $\mathrm{Ni}$ (II) surface to a predominantly $\mathrm{Ni}$ (III) surface may facilitate increased charge separation at the nickel hydroxide/electrolyte interface. Thus the $C_{d l}$ element may not just represent the double-layer capacitance, but also contain contributions from a faradaic pseudo-capacitance arising from the $\mathrm{Ni}(\mathrm{II}) / \mathrm{Ni}(\mathrm{III})$ redox transition. However, it is worth noting that this increase in $C_{d l}$ could also be due to the adsorption of intermediates as discussed below. The variation of $R_{p}$ as a function of applied potential is also shown in Fig. 8a. The polarisation resistance $R_{p}$ can be viewed as a total charge transfer resistance for the combined steps of a multi-step reaction. In the theoretical treatment of Harrington and Conway (20), the reciprocal resistance $1 / R_{p}$ was shown to be equal to the sum of similar reciprocal resistances for each of the individual charge transfer steps. Consequently, $R_{p}$ is related to the overall rate of the glucose oxidation reaction. As expected for a Faradaic process, $R_{p}$ decreases with increasing potential indicating an enhancement in the electron transfer kinetics. It is interesting that no further decrease in $R_{p}$ is observed for potentials more anodic than the $\mathrm{Ni}(\mathrm{II}) / \mathrm{Ni}(\mathrm{III})$ peak potential. This suggests that the oxidation of glucose is independent of potential once the generation of $\mathrm{NiOOH}$ at the electrode surface becomes sufficiently facile.

Fig. 8b shows the variation of the $C_{\phi}$ and $R_{s}$ circuit elements with applied potential. It has been noted that the $C_{\phi} R_{s}$ loop in the equivalent circuit models the relaxation of charge associated with a surface intermediate (20). In this sense, $C_{\phi}$ can be related to the concentration of surface intermediates in the glucose electro-oxidation process. It is clear 
from Fig. $8 \mathrm{~b}$ that $C_{\phi}$ was small and independent of potential at potentials below the $\mathrm{Ni}(\mathrm{II}) / \mathrm{Ni}(\mathrm{III})$ peak potential. In contrast, $C_{\phi}$ increased significantly for potentials where the nickel hydroxide layer was predominantly in the $\mathrm{NiOOH}$ form. This observation implies that the adsorption process preferentially involves the $\mathrm{NiOOH}$ species over the $\mathrm{Ni}(\mathrm{OH})_{2}$ species, in agreement with the early work of Fleischmann and coworkers (9a, 12). Interestingly, the behaviour of the $R_{s}$ element mirrors that of $C_{\phi}$. Initially, $R_{s}$ is independent of potential but then begins to increase along with $C_{\phi}$. Harrington and Conway (20) have shown that $R_{s}$ is related, albeit in a rather complicated fashion, to the rate of production of one or more surface intermediates. In a general way, $R_{s}$ gives an indication of the ease with which these species can be formed. Thus, this result suggests that as the potential is increased it becomes increasingly difficult for the intermediates to adsorb to the surface $\mathrm{NiOOH}$ species. The reason for this is uncertain but it may indicate adsorption saturation at the higher potentials.
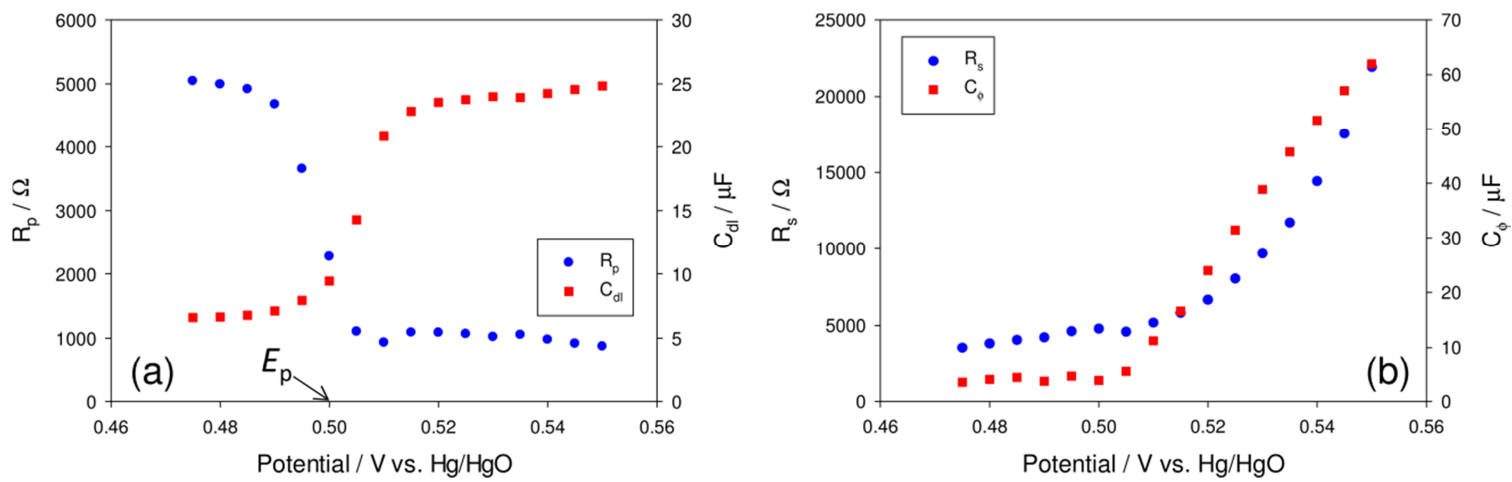

Figure 8. The optimum fitting values of (a) $R_{p}$ and $C_{d l}$, and (b) $R_{s}$ and $C_{\phi}$ plotted as a function of the applied potential for a nickel hydroxide modified Au electrode in a $1.0 \mathrm{M}$ $\mathrm{NaOH}$ solution containing $10 \mathrm{mM}$ glucose.

\section{$\underline{\text { Mechanism of Glucose Electro-Oxidation }}$}

Mechanistic studies of the electro-oxidation of glucose at the nickel hydroxide modified $\mathrm{Au}$ electrode are ongoing in our laboratory, therefore a detailed discussion is beyond the scope of this article. However, it is informative to interpret the results outlined above in relation to a commonly accepted mechanism from the literature. Fleischmann and coworkers (12) proposed the following general mechanism for the oxidation of a number of organic compounds including glucose:

$$
\begin{gathered}
\mathrm{Ni}(\mathrm{OH})_{2}+\mathrm{OH}^{-} \rightarrow \mathrm{NiOOH}+\mathrm{H}_{2} \mathrm{O}+\mathrm{e}^{-} \\
{[\text {Glucose }]_{\mathrm{sol}} \rightarrow[\mathrm{Glucose}]_{\mathrm{ads}}} \\
\mathrm{NiOOH}+[\text { Glucose }]_{\text {ads }} \rightarrow \mathrm{Ni}(\mathrm{OH})_{2}+\text { radical intermediate } \\
\text { Radical intermediate }+2 \mathrm{NiOOH} \rightarrow 2 \mathrm{Ni}(\mathrm{OH})_{2}+\text { gluconolactone }+2 \mathrm{e}^{-}
\end{gathered}
$$

Based on this mechanism a number of conclusions can be inferred from the kinetic studies presented here. Firstly, the voltammetric response of the nickel hydroxide modified $\mathrm{Au}$ electrode to various glucose concentrations supports the literature consensus that $\mathrm{NiOOH}$, possibly $\beta-\mathrm{NiOOH}$, catalyses the electro-oxidation of glucose $(9 \mathrm{a}, 12,18)$. Secondly, the potential dependence of the $C_{\phi}$ circuit element indicates that adsorption becomes significant when the film is in the $\mathrm{NiOOH}$ form, as suggested by Fleischmann and coworkers (12). Finally, the mass-transport-corrected Tafel analysis points to a 
change in RDS with increasing potential. This concept is also apparent in the EIS results where the $R_{p}$ circuit element was found to be potential dependent at low potentials but independent of potential at high potentials. In the case of multi-step reactions such as the electrocatalytic oxidation of glucose the experimentally observed Tafel slope can be shown to be (23),

$$
b=2.303(R T / \alpha F)
$$

where $R, T$ and $F$ have their usual meanings and the transfer coefficient $\alpha$ is given by,

$$
\alpha=(n / v)+n_{r} \beta
$$

where $n$ is the number of electrons transferred before the RDS, $v$ is the stoichiometric number defined as the number of times the RDS occurs for one repetition of the overall reaction, $n_{r}$ is the number of electrons transferred in each occurrence of the RDS and $\beta$ is the symmetry factor which is generally taken to be $1 / 2$. In this way, it can be seen that the Tafel slope is a composite parameter, giving information on the stoichiometry and the succession of steps in the overall reaction. In Fleischmann's mechanism above, it is assumed that the initial two steps are fast whereas the third step, involving hydrogen extraction from an adsorbed glucose molecule in eqn[12], is rate-limiting (12). For this purely chemical step $n=1, n_{r}=0$ and, assuming $v=1$, we get $\alpha=1$ predicting a Tafel slope of $c a .60 \mathrm{mV} / \mathrm{dec}$ at $25^{\circ} \mathrm{C}$. This value is in good agreement with the Tafel slope reported here at high oxidative potentials suggesting that eqn[12] is rate-limiting. It is noteworthy that eqn[12] also represents the removal of an adsorbed species from the surface. Thus, if this step is rate-limiting then adsorption saturation is probable at high potentials, which would account for the increasing value of the $R_{s}$ circuit element with potential. In contrast, the Tafel slope of $c a .40 \mathrm{mV} / \mathrm{dec}$ observed at low potentials can be rationalised if $n=1, n_{r}=1$ and $v=1$. This implies that the second electron transfer step, corresponding to the initial oxidation of the radical intermediate in eqn[13], is ratelimiting at low potentials. Examining eqn[13] it is clear that this step depends significantly on the concentration of $\mathrm{NiOOH}$ surface sites. Therefore it is not unreasonable for this step to be rate-limiting at low potentials where there is limited oxidation of the nickel hydroxide film.

\section{Amperometric Sensor Applications of the Nickel Hydroxide Film}

The performance of the nickel hydroxide modified Au electrode as an amperometric glucose sensor was assessed using a rotating disk electrode (RDE). In these experiments the nickel hydroxide coated electrode was rotated at $1500 \mathrm{rpm}$ in $50 \mathrm{~cm}^{3}$ of $1.0 \mathrm{M} \mathrm{NaOH}$ to which small volumes of a standard $0.10 \mathrm{M}$ solution of glucose were added. The electrode potential was held at $0.6 \mathrm{~V}$, where the oxidation current was transport controlled (Fig. 6a) and the regeneration of $\mathrm{NiOOH}$ at the electrode surface would be facile (Fig. 5). The electrodes were then held at this potential for $10 \mathrm{~min}$ prior to injection of the glucose aliquots in order to ensure a stable background current. A typical amperometric response to a series of glucose injections is illustrated in Fig. 9. One important parameter to quantify is the speed of the sensor response as this will be significant from the point of view of practical applications. It can be seen from Fig. 9 that the nickel hydroxide modified Au electrode responded rapidly to the glucose additions with response times of $c a .3-5 \mathrm{~s}$. The calibration plot generated from the amperometric 
data is shown in the inset of Fig. 9. Good linearity is observed for the sensor over an extended range of glucose concentrations, from micromolar up to high millimolar levels. This is significant in that it indicates that the electrode is not subject to fouling or loss of sensitivity even at high glucose levels. From the slope of the calibration plot the sensitivity was determined to be $3.7 \mathrm{~mA} \mathrm{mM} \mathrm{mm}^{-1}$ and the limit of detection was calculated as $2.0 \mu \mathrm{M}$ using $3 \sigma(24)$. These values compare favorably with literature results (5). Indeed the nickel hydroxide based sensor described here is among the most sensitive reported.

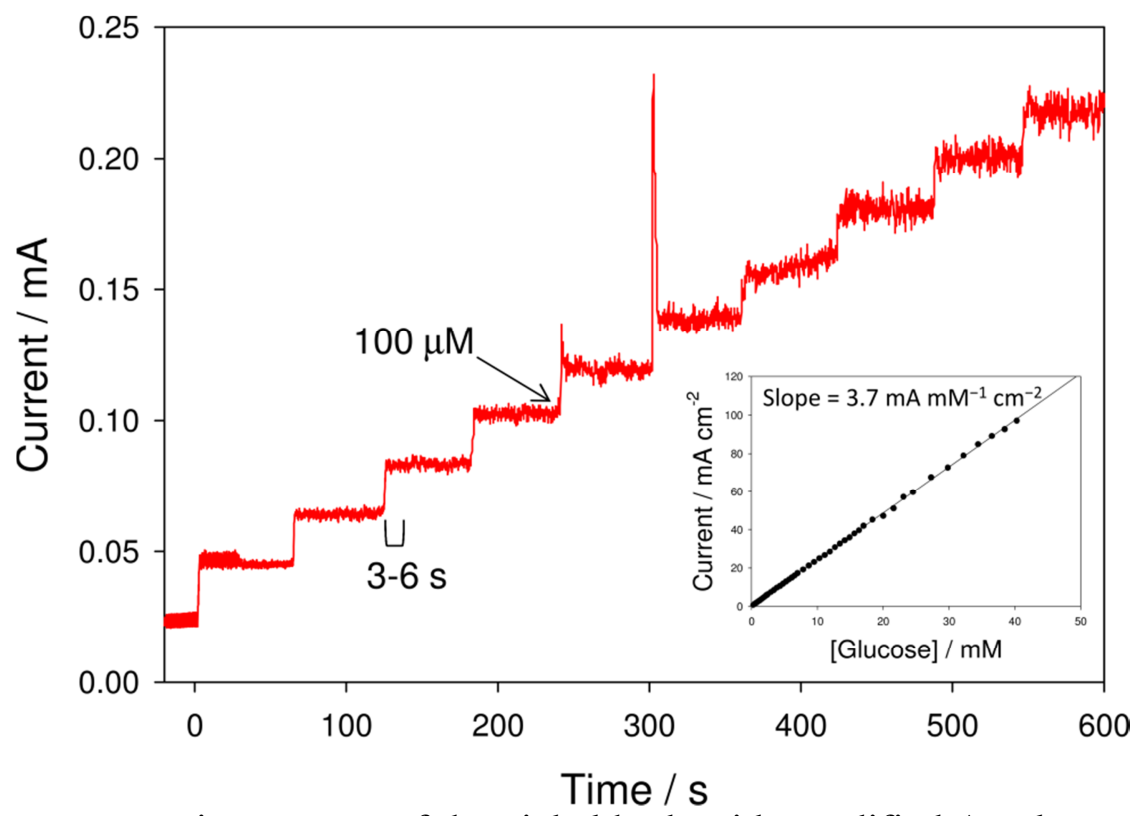

Figure 9. Amperometric response of the nickel hydroxide modified Au electrode in $1.0 \mathrm{M}$ $\mathrm{NaOH}$ to a series of $100 \mu \mathrm{M}$ glucose additions. The electrode was held at a constant potential of $0.6 \mathrm{~V}$ and rotated at $1500 \mathrm{rpm}$. The inset shows a plot of steady-state current after each aliquot addition as a function of the solution glucose concentration.

\section{Conclusions}

In conclusion, we have described the fabrication of a simple yet highly effective nonenzymatic glucose sensor based on a nickel hydroxide film modified electrode. The sensor can be easily prepared using a potential multicycling procedure which deposits a nanostructured layer of nickel hydroxide on the electrode surface. The oxidation of glucose was shown to be catalyzed by the $\mathrm{NiOOH}$ form of the nickel hydroxide layer. In particular, electrochemical impedance studies indicate that adsorption of intermediates occurs preferentially at the $\mathrm{NiOOH}$ sites. Furthermore, a change in the rate-determining step with increasing potential was identified in both the Tafel analysis and electrochemical impedance studies. Mass-transfer-corrected Tafel slopes of ca. $40 \mathrm{mV} / \mathrm{dec}$ and $60 \mathrm{mV} / \mathrm{dec}$ were observed at low and high potentials respectively, while the polarization resistance changed from potential dependent to potential independent over the same respective potential regions. These results have been interpreted in terms of a classic mechanism proposed by Fleischmann and coworkers (12) for the electrocatalytic oxidation of organic compounds. Finally, the nickel hydroxide modified electrode was shown to be a promising amperometric glucose sensor exhibiting excellent sensitivity, 
with current increases of $c a .3 .7 \mathrm{~mA} \mathrm{mM}^{-1} \mathrm{~cm}^{-2}$, and a limit of detection of $c a .2 .0 \mu \mathrm{M}$ glucose.

\section{Acknowledgments}

This publication has emanated in part from research conducted with the financial support of Science Foundation Ireland (SFI) under grant number SFI/10/IN.1/I2969. We also wish to thank the Advanced Microscopy Laboratory (AML) in the Centre for Research on Adaptive Nanostructures and Nanodevices (CRANN) at Trinity College Dublin for their help with the SEM analysis.

\section{References}

1. E. Katz, I. Willner and A.B. Kotlyar, J. Electroanal. Chem., 479, 64 (1999).

2. A. Heller and B. Feldman, Chem. Rev., 108, 2482 (2008).

3. J. Wang, Chem. Rev., 108, 814 (2008).

4. R. Wilson and A. P. F. Turner, Biosens. Bioelectron., 7, 165 (1992).

5. K. E. Toghill and R. G. Compton, Int. J. Electrochem. Sci., 5, 1246 (2010).

6. S. Park, H. Boo and T. D. Chung, Anal. Chim. Acta., 556, 46 (2006).

7. (a) Y.-J. Lee, D.-J. Park, J.-Y. Park, and Y. Kim, Sensors, 8, 6154 (2008). (b) J.-F. Huang, Electroanalysis, 20, 2229 (2008). (c) Z. Cao, Y. Zou, C. Xiang, L.-X. Sun and F. Xu, Anal. Lett., 40, 2116 (2007). (d) E. Skou, Electrochim. Acta, 22, 313 (1977).

8. (a) A. Hilmi and J. H. T. Luong, Anal. Chem., 72, 4677 (2000). (b) Y. Li, Y.-Y. Song, C. Yang and X.-H. Xia, Electrochem. Commun., 9, 981 (2007). (c) Y.-G. Zhou, S. Yang, Q.-Y. Qian and X.-H. Xia, Electrochem. Commun., 11, 216 (2009). (d) S. Cho and C. Kang, Electroanalysis, 19, 2315 (2007). (e) L. E. Welch, D. A. Mead Jr. and D. C. Johnson, Anal. Chim. Acta, 204, 323 (1988).

9. (a) M. Fleischmann, K. Korinek and D. Pletcher, J. Electroanal. Chem. Interfacial Electrochem., 31, 39 (1971). (b) M. Jafarian, F. Forouzandeh, I. Danaee, F. Gobal, and M. G. Mahjani, J. Solid-State Electrochem., 13, 1171 (2009). (c) A. Salimi and M. Roushani, Electrochem. Commun., 7, 879 (2005). (d) C. Zhao, C. Shao, M. Li, and K. Jiao, Talanta, 71, 1773 (2007). (e) M. Morita, O. Niwa, S. Tou and N.Watanabe, J. Chromatogr., A 837, 17 (1999). I. Danaee, M. Jafarian, F. Forouzandeh, F. Gobal and M. G. Mahjani, Electrochim. Acta, 53, 6602 (2008). (f) L. A. Hutton, M. Vidotti, A. N. Patel, M. E. Newton, P. R. Unwin and J. V. Macpherson, J. Phys. Chem. C, 115, 1649 (2011). (g) K. E. Toghill, L. Xiao, M. A. Phillips and R. G. Compton, Sens. Actuators B, 147, 642 (2010).

10. (a) L. A. Colon, R. Dadoo and R. N. Zare, Anal. Chem., 65, 476 (1993). (b) T.-K. Huang, K.-W. Lin, S.-P. Tung, T.-M. Cheng, I. C. Chang, Y.-Z. Hsieh, C.-Y. Lee and H.-T. Chiu, J. Electroanal. Chem., 636, 123 (2009). (c) C. BatchelorMcAuley, Y. Du, G. G. Wildgoose and R. G. Compton, Sens. Actuators B, B135, 230 (2008). (d) A. Stitz and W. Buchberger, Electroanalysis, 6, 251 (1994). (e) T. A. Ivandini, R. Sato, Y. Makide, A. Fujishima and Y. Einaga, Diamond Relat. Mater., 13, 2003 (2004).

11. (a) J. Lee and S.-M. Park, Anal. Chim. Acta, 545, 27 (2005). (b) S. Y. Ly, Curr. Anal. Chem., 5, 59 (2009). (c) J.-S. Ye, Y. Wen, W. D. Zhang, L. M. Gan, G. Q. 
Xu and F.-S. Sheu, Electrochem. Commun., 6, 66 (2004). (d) J. Wang, X. Sun, X. Cai, Y. Lei, L. Song and S. Xie, Electrochem. Solid-State Lett., 10, J58 (2007).

12. M. Fleischmann, K. Korinek and D. Pletcher, J. Chem. Soc. Perkin Trans., 2, 1396 (1972).

13. Q. Yi, W. Huang, W. Yu, L. Li and X. Liu, Electroanalysis, 20, 2016 (2008).

14. M. Fantini and A. Gorenstein, Solar Energy Mater., 16, 487 (1987).

15. (a) M. E. G. Lyons, L. Russell, M. O’Brien, R. L. Doyle, I. Godwin, M. P. Brandon, Int. J. Electrochem. Sci., 7, 2710 (2012). (b) M. E. G. Lyons, R. L. Doyle, I. Godwin, M. O'Brien and L. Russell, J. Electrochem. Soc., 159, H932 (2012).

16. (a) M. E. G. Lyons, A. Cakara, P. O'Brien, I. Godwin and R. L. Doyle, Int. J. Electrochem. Sci., 7, 11768 (2012). (b) G. W. D. Briggs and M. Fleischmann, Trans. Faraday Soc., 62, 3217 (1966).

17. H. Bode, K. Dehmelt and J. Witte, Electrochim. Acta, 11, 1079 (1966).

18. P. Oliva, J. Leonardi, J. F. Laurent, C. Delmas, J. J. Braconnier, M. Figlarz, F. Fievet and A. De Guibert, J. Power Sources, 8, 229 (1982).

19. W. J. Albery, Electrode Kinetics, p. 49, Clarendon Press, Oxford (1975).

20. D. A. Harrington and B. E. Conway, Electrochim. Acta, 32, 1703 (1987).

21. B. E. Conway and E. Gileadi, Trans. Faraday Soc., 58, 2493 (1962).

22. B. E. Conway, in Impedance Spectroscopy-Theory, Experiment, and Applications, E. Barsoukov and J. R. Macdonald, Editors, p. 469, J. Wiley \& Sons, New York (2005).

23. R. L. Doyle, I. J. Godwin, M. P. Brandon and M. E. G. Lyons, Phys. Chem. Chem. Phys., (2013) DOI: 10.1039/c3cp51213d.

24. C. M. Brett and A. M. O. Brett, Electroanalysis, Oxford University Press, Oxford (1998). 